\title{
Processo de construção musical do objeto virtual de aprendizagem Saladança de Frutas *
}

\author{
Fátima Weber Rosas -UFRGS - fatima@ caef.ufrgs.br ${ }^{1}$ \\ Professora Dra. Helena de Souza Nunes - UFRGS - helena@caef.ufrgs.br ${ }^{2}$
}

\begin{abstract}
Resumo: Este trabalho relata a experiência de criação da base instrumental para a canção-tema do CD-ROM denominado Saladança de Frutas, o qual surge no contexto da disciplina Projeto Interdisciplinar, do Curso de Especialização, na modalidade à distância, denominada Artes e Educação Física na Educação Básica (Porto Alegre, UFRGS, 2007). A produção deste componente musical implica concepções para criação de trilhas sonoras destinadas a objetos virtuais de aprendizagem. Sendo assim, o processo descrito, cujo desenvolvimento foi baseado na Proposta Musicopedagógica CDG, é discutido à luz do documento intitulado Referenciais para Elaboração de Material Didático para EAD no Ensino Profissional e Tecnológico, do MEC.
\end{abstract}

Palavras chave: Objeto virtual de aprendizagem, interatividade, interdisciplinaridade, tecnologia.

\section{Process of musical construction of the learning object Saladança of Fruits}

\begin{abstract}
This paper reports the experience of the instrumental base creation for the theme-song of the CD-ROM called Saladança de Frutas, which comes from the context of the topic Projeto Interdisciplinar, from the Specializing Course, taken on-line, named Artes e Educação Física na Educação Básica (Porto Alegre, UFRGS, 2007). The production of this musical component implies into conceptions for the creation of soundtracks destined to learning objects. Given this, the process above mentioned, whose development was based on the Musicpedagogical Proposal, is discussed with the document entitled Referenciais para Elaboração de Material Didático para EAD no Ensino Profissional e Tecnológico, from the Ministry of Education (MEC).
\end{abstract}

Keywords: Object of learning, interactivity, interdisciplinarity, technology.

\footnotetext{
* Trabalho de Conclusão do Curso de Especialização em Artes e Educação Física na Educação Básica do CINTED/UFRGS.

${ }^{1}$ Integrante do grupo de pesquisa Proposta Musicopedagógica CDG (PROPESQ da UFRGS e Diretório de Grupos de Pesquisa do CNPq).

2 Professora do Departamento de Música do Instituto de Artes da UFRGS, coordenadora do projeto CAEF da UFRGS, integrado à Rede Nacional de Formação Continuada da SEB/MEC, e do curso Licenciatura em Música EAD, do Programa Pró-Licenciaturas da SEED/MEC. Autora do método MAaV e pesquisadora responsável pelo grupo de pesquisa Proposta Musicopedagógica CDG (PROPESQ da UFRGS e Diretório de Grupos de Pesquisa do CNPq).

V. 6 № 1, Julho, 2008
} 


\section{INTRODUÇÃO}

Diante das novas tecnologias, da influência dos meios de comunicação e da Internet, sente-se a necessidade de reformular a Educação, para atender os reais anseios e necessidades de uma sociedade globalizada e em rápidas transformações. No final do século XX, a educação entra num período de tensão e transição, caracterizado pela busca de uma educação mais aberta ao diálogo e à crítica, veiculada pelo emprego de tecnologias digitais, e desenvolvida em projetos coletivos. Chega-se assim à formulação dos quatro pilares da Educação do século XXI, quais sejam saber fazer, saber aprender, saber conviver e saber ser. (Bassani, 2000). Segundo (Nunes, 2005), para fazer frente a tantos desafios, a Proposta Musicopedagógica CDG desenvolve seus produtos, como a canção em foco, numa abordagem multi-modal.

Dentro de uma perspectiva interdisciplinar e utilizando novas tecnologias educacionais, alguns alunos do Curso de Especialização, na modalidade à distância, Artes e Educação Física na Educação Básica (Porto Alegre, UFRGS, 2007) deram início à criação de um Objeto Virtual de Aprendizagem. Esta tarefa foi realizada por intermédio de construção cooperativa do conhecimento, um trabalho de autoria colaborativa interdisciplinar, numa abordagem metodológica que envolveu Artes Visuais, Dança, Música, Pedagogia e Educação Física.

O resultado concreto foi um CD-ROM, empregando variados recursos multimídia, chamado Saladança de Frutas, por ter sido criado a partir da canção de mesmo nome (Cunha, 2001 apud Nunes, 2005), cujas partes também podem ser utilizadas separadamente.

\section{REFERENCIAL TEÓRICO}

\subsection{OBJETO VIRTUAL DE APRENDIZAGEM}

O termo objeto de aprendizagem vem do inglês learning objects (LO). (Nunes, 2004 apud Wiley, 2000, p.01) apresenta, para learning objects, a definição "qualquer recurso digital que possa ser reutilizado e ajude na aprendizagem". De acordo com Nunes (2004), as palavras digital, reutilizável e aprendizagem são consideradas chaves ao se falar de objeto de aprendizagem. Esses materiais também são conhecidos como multimídias interativas para educação, e têm a função de facilitar a aprendizagem, tornando-a prazerosa, devido ao uso de jogos e atividades virtuais interativas. A questão da interatividade pressupõe que o aluno não somente associe e assimile, mas também interaja com o objeto de estudo. Para (Tarouco e Ávila, 2007, p.03):

\footnotetext{
Numa sociedade com as possibilidades tecnológicas da atual, a mediação textual da aprendizagem e da construção do conhecimento não pode limitar-se apenas ao texto como livro já que a tecnologia evoluiu e permite maior variedade de possibilidades. $\mathrm{O}$ projeto deste tipo de material deve levar em conta tanto considerações derivadas de teorias de aprendizagem [...] e levar ainda em conta as potencialidades e limitações da tecnologia envolvida e isto significa atualmente utilizar a multimídia como recurso de apoio no processo de ensino-aprendizagem.
} 
Segundo a empresa Microsoft, que atualmente tem dado apoio à produção de objetos de aprendizagem no Brasil, o primeiro objeto de aprendizagem em nosso país teve início em 2000. (Gallota, 2005), no site da Microsoft Corporation, faz a seguinte afirmação:

[...] Com os LOs, os professores podem ensinar com mais eficiência e os alunos aprendem brincando, ou brincam aprendendo. Partindo de exemplos práticos para despertar a curiosidade dos estudantes, os objetos de aprendizagem têm se tornado uma importante ferramenta para aprimorar o ensino interativo de temas didáticos das mais diversas disciplinas.

A interatividade representa um novo paradigma de aprendizagem. (Romiszowski, 2000, p.05) afirma:

Criar e desenvolver atividades educacionais interativas significa criar um novo paradigma de aprendizagem, no qual o aluno ao invés de ouvir e assimilar, interage ativamente com a tecnologia (termo aqui usado para hardware e software).

Buscando alternativas para o conhecimento isolado e proprietário, o desenvolvimento do CD-ROM Saladança de Frutas, iniciado em maio de 2007, vem sendo criado em autoria colaborativa, garantindo-se assim uma perspectiva aberta. (Bassani, 2000, p.21) afirma:

A interdisciplinaridade é uma prática individual, coletiva, crítica e criativa. É considerada prática individual, enquanto exige de cada profissional a competência do conhecimento em sua área de trabalho [...]. É considerada prática coletiva, exigindo linguagem e objetivos comuns, incluindo descentralização nas relações de poder, pois as disciplinas são consideradas de igual valor.

Por fim, ainda justificando o CD-ROM em discussão como um objeto virtual de aprendizagem, segundo os Referenciais do MEC, (Brasil, 2007, p.02):

[...] A produção de material didático para $\mathrm{EaD}$ deve tornar-se uma construção coletiva e uma obra aberta, num processo educativo sistemático, organizado e continuado, usando ferramentas de comunicação na mediação entre professor e aluno.

Confirma-se, assim, que o CD Saladança de Frutas pode ser considerado um objeto virtual de aprendizagem, pois tem construção coletiva, é uma obra aberta, ensina conteúdos da área de Artes de forma lúdica, possuindo recursos multimídia, tais como vídeos, animações, arquivos áudio e jogos interativos, os quais também podem ser individualmente reutilizados em outros contextos.

\subsection{REFERENCIAIS DO MEC PARA ELABORAÇÃO DE MATERIAL DIDÁTICO PARA EAD}


A tarefa de promover a criação, o aprofundamento e os posteriores detalhamentos dos materiais didáticos para a WEB jamais se acaba. À medida que cursos forem sendo realizados e a utilização desses objetos de aprendizagem for efetivamente operacionalizada, haverá novas e crescentes possibilidades de reformulação desses. A grande meta será sempre a potencialização da aprendizagem autônoma associada à experiência, mediada pela internet. Buscando sistematizar e orientar as muitas iniciativas que hoje se multiplicam no país, em julho de 2007, a Secretaria de Educação à Distância e a Secretaria de Educação Profissional e Tecnológica, ambas do MEC, produziram o documento Referenciais para Elaboração de Material Didático para EAD no Ensino Profissional e Tecnológico.

Dentre as diretrizes relevantes para a construção de materiais didáticos, destacase neste CD-ROM:

- A identificação e a caracterização da demanda, no caso, formada por professores da Educação Básica;

- A definição clara de objetivos gerais e específicos orientadores da aprendizagem, uma vez que busca fornecer subsídios a esses professores, para que tanto utilizem o material em seu estado original, como possam reutilizar seus módulos na criação de novos materiais;

- A integração das diversas mídias, buscando a complementaridade, como animação, hipertextos, jogos e, o foco deste relato, arquivos áudio;

- O desenvolvimento da afetividade, da cidadania e da ética, por intermédio das atividades propostas;

- A conservação do material didático produzido em um repositório, de momento, o ROE (www.caef.ufrgs.br/roe), e posteriormente, diversos outros;

- A possibilidade de parcerias na produção interinstitucional do material didático, à medida que os alunos do curso de Especialização também estão vinculados a diversas instituições de ensino, em todo o país;

\section{CANÇÃO SALADANÇA DE FRUTAS}

\subsection{FOCO E OBJETIVOS}

O CD-ROM Saladança de Frutas tem a finalidade didática de oferecer subsídios aos professores do Ensino Fundamental e Médio, auxiliando a sua prática docente, numa abordagem pedagógica, que procura atingir as necessidades afetivas, cognitivas, corporais, sociais e éticas dos educandos, na área de Artes. No que se refere à Música, apresenta a canção em três arquivos áudios distintos, quais sejam, (1) interpretação completa, (2) execução apenas da linha melódica, e (3) gravação das bases instrumentais. A experiência aqui relatada consiste do processo de criação dessas bases instrumentais para acompanhamento das vozes infantis que cantaram a linha melódica da canção Saladança de Frutas. Com base neste relato, é possível refletir sobre a produção de componentes musicais, as chamadas Trilhas Sonoras, em objetos virtuais de aprendizagem. 
A principal razão da escolha desta canção específica é sua estrutura musical e seu texto, os quais proporcionam múltiplas formas de exploração pelas diversas áreas de conhecimento, facilitando a interdisciplinaridade recomendável a um objeto virtual de aprendizagem. Já a interatividade pode ser verificada na oferta de experiências diversas com materiais visuais e sonoros, explorando os sentidos, a memória, a compreensão, a emoção, e a criatividade. Sendo assim, as bases instrumentais gravadas e disponíveis como arquivos áudios independentes podem ser utilizados por um professor não instrumentista, como apoio ao canto e à dança de seus alunos.

\subsection{ESTRUTURA MUSICAL}

Na peça musical Saladança de Frutas, a autora desenvolve dois temas: um estritamente musical e outro referente ao texto. A forma musical é unária, cujo desenvolvimento se dá numa estrutura de pout-pourri, onde se observa uma colagem de cinco estilos de danças: xote, valsa, rock, marcha e tango. Associando nomes de frutas com diferentes estilos musicais, cria momentos de caráter particular e característico.

Esta estrutura favorece uma analogia com uma salada de frutas, onde os sabores e as cores, assim como perceptíveis isoladamente, também são misturados, formando um novo conjunto muito diferenciado e próprio. Ao longo da apresentação das diferentes danças, com as correspondentes mudanças de compasso, a unidade rítmica da obra é garantida pela permanência da pulsação, que, mesmo sustentando variações em natureza e tipos de agrupamento, se mantém ao longo da peça.

Com o intuito de preservar esta característica, optou-se por realizar um arranjo típico a cada uma das cinco partes da canção, onde as diversas danças representassem países distintos. Desta forma, acaba-se por fazer também uma "salada de timbres instrumentais" e uma "salada de países": o xote gaúcho, representando o Brasil, a valsa vienense, representando a Áustria, o rock norte-americano estilo Elvis Presley, representando os EUA, a marcha com características da bandinha alemã, representando a Alemanha, e o tango argentino, representando a Argentina.

\subsection{PROCESSO DE GRAVAÇÃO}

A canção Saladança de Frutas apresenta várias mudanças de compasso. Essa foi uma das maiores dificuldades encontradas durante a gravação do acompanhamento e do canto. Para possibilitar a integração entre as diferentes vozes do arranjo e, posteriormente, com o canto, era preciso manter um referencial rítmico comum a todas as estruturas empregadas. Ao mesmo tempo, era preciso explicitar o andamento distinto e o caráter próprio de cada uma das partes.

Devido a uma limitação do software, não era possível mudar o compasso durante a gravação; somente depois dela. Por isso foram feitas tentativas de colagem das partes (danças) na edição do áudio, mas o resultado não foi satisfatório. Então, a canção foi gravada em compasso unário, 1/1, cujo metrônomo ficou em 400 batidas por minuto. Desta forma, foi possível manter uma pulsação permanente do início ao fim da obra, a qual serviu de referencial comum às menores figurações rítmicas de cada uma das 
danças. Para realizar a gravação das bases instrumentais da canção Saladança de Frutas foram utilizados os softwares Sonar, ProTools, Cool Edit Pro e Sound Forge.

A produção dos diferentes timbres instrumentais foi originalmente gravada em formato MIDI (Musical Instrument Digital Interface), por intermédio do teclado Workstation Roland XP-60, sintetizador que gerou a obra. O software Sonar permite a gravação de cada timbre em trilhas ou tracks separados, possibilitando a escuta e o reaproveitamento isolado das mesmas. Além dos timbres instrumentais, a canção Saladança de Frutas apresenta texto e, portanto, necessita da presença de vozes, que conduziu ao emprego do formato MP3.

\section{RESULTADOS OBTIDOS E DISCUSSÃO}

\subsection{ASPECTOS TECNOLÓGICOS}

Uma das primeiras definições num trabalho deste tipo se refere ao emprego dos softwares de autoria, o que implica a compatibilidade entre formatos de arquivos deles resultantes, e ao suporte para veiculação do produto final obtido. O Saladança de Frutas também passou e, de uma certa forma, ainda passa por esta discussão, à medida que se amplia.

Para a gravação dos instrumentos, escolheu-se o formato Musical Instrument Digital Interface, que estabelece comunicação entre instrumentos musicais e equipamentos eletrônicos como PCs, sintetizadores, seqüenciadores, teclados, entre outros. Esse formato, o MIDI, ocupa pouco espaço dentro dos discos e, apesar de não comportar o áudio em si, possui comandos que definem toda a composição musical (ritmo, efeitos, timbres, notas, instrumentos, entre outros componentes), juntamente com um sintetizador gerador da obra.

A partir dos arquivos em formato MIDI, seria possível executar, manipular e transmitir as criações musicais das bases instrumentais em diversos dispositivos. Para o formato final das três trilhas já produzidas optou-se pelo MP3 (MPEG-Audio Layer-3), que, além de ser um tipo de arquivo que comporta áudio e é compatível com muitos tocadores e softwares, compacta os mesmos, deixando-os menores e facilitando seu tráfego pela rede.

Com relação ao suporte e à veiculação do trabalho produzido, inicialmente, pensou-se somente em formato de CD-ROM. De acordo com (Mehlecke e Tarouco, 2003), o CD-ROM é um dos recursos que promove a comunicação no sistema de Educação a Distância, auxiliando os alunos com maior dificuldade de acesso à Internet. No entanto, reduz seu alcance. Devido a isso, planeja-se divulgá-lo também pela Internet. Porém, essa possibilidade tem diversas implicações relacionadas, por exemplo, ao público-alvo do trabalho e aos arquivos de imagens também integrantes deste objeto virtual de aprendizagem (ilustrações, animações, filmes). No momento, esta discussão não apenas foge ao foco deste artigo, como ainda está sendo desenvolvida. 


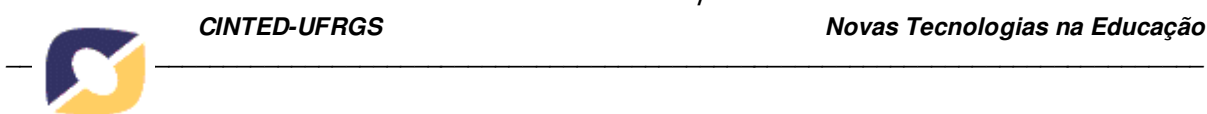

\subsection{ASPECTOS MUSICAIS}

Ao se realizar o arranjo instrumental da canção, procurou-se incluir instrumentos característicos de cada dança que integra seu pout-pourri. Para isso, foi realizado um estudo, o qual incluiu entrevistas e a escuta crítica de exemplos musicais fidedignos a cada estilo de dança, considerando-se contextos de seus respectivos países de origem.

Essa busca resultou, por exemplo, no emprego de diferentes timbres de Contrabaixos, posto que cada estilo de dança utiliza um instrumento distinto para executar a linha de Baixo (acústico, de orquestra ou grupos de jazz, elétrico). Esta parte do trabalho foi realizada com o apoio do Dr. Luciano Antônio Dalmolin, professor de Contrabaixo do Instituto de Artes da UFRGS. Já decisões referentes aos instrumentos pertencentes à Banda Alemã, no caso, empregada na Marcha, resultou de uma visita ao Museu Visconde de São Leopoldo, de uma entrevista com o Sr. Walter Seger de Pinhal Alto -RS, e ainda pela observação de fotos de uma Bandinha Alemã da cidade de Bom Princípio-RS e de uma Bandinha Alemã de São Leopoldo-RS. Para subsidiar a criação do xote gaúcho, por sua vez, foi feita uma entrevista com a professora de danças gaúchas e freqüentadora de CTGs (Centro de Tradições Gaúchas) Sra. Elisandra Herold e o ex-integrante de CTG, Sr. Luiz Gustavo da Silva, além de buscas na internet. Os instrumentos presentes nas demais danças da peça foram escolhidos a partir da análise de obras representativas e da audição de exemplos musicais fidedignos ao seu estilo e gênero, na literatura musical de consagradas gravadoras.

Além de pesquisa sobre os estilos e ritmos característicos das danças, levou-se em consideração a extensão e as sonoridades próprias de cada instrumento utilizado no arranjo, procurando produzir a maior fidelidade possível entre seus timbres reais e os timbres eletrônicos do teclado, onde efetivamente estavam sendo executados. Esta prática, naturalmente, não é a ideal. Bem melhor seria que os professores de Música tivessem orquestras, bandas e outros grupos musicais à sua disposição, permanentemente. Porém, não sendo esta a realidade, pode-se encontrar soluções alternativas, como as aqui descritas.

\subsection{ESTILOS DA BASE DE ACOMPANHAMENTO}

Durante o processo de gravação da canção Saladança de Frutas, tentou-se reproduzir os sons de instrumentos musicais diversos, utilizando um teclado e softwares. Foi necessário levar em conta não somente a extensão de cada instrumento, mas também as características e possibilidades sonoras dos mesmos. Tais recursos, devidamente associados aos estilos próprios a cada dança, estabelecem os fundamentos dos arranjos produzidos.

$\mathrm{Na}$ visão do tradicionalismo gaúcho, em invernadas, os instrumentos típicos utilizados para a execução do Xote são: pandeiro confeccionado com couro, gaita e violão (ou viola de 12 cordas). Os timbres instrumentais escolhidos para o Xote que aparece entre os compassos 1 a 12 foram a gaita e o violão.

A Valsa, que aparece nos compassos 13 e 14, surgiu a partir de 1825, sendo tradicionalmente tocada pela orquestra, em sua forma popularmente mais conhecida. $\mathrm{Na}$ procura por uma maior aproximação e fidelidade ao estilo, conforme descrito por (Kiefer, 1973), buscou-se a constituição e a instrumentação típicas das orquestras do 
período clássico e romântico, sendo que este último foi o período do auge das valsas austríacas.

Já o Rock tem múltiplas formas e características, todas bastante populares. Optou-se pela simplicidade do Rock anos 60, com inspiração Elvis Presley, que emprega bateria, guitarra, contrabaixo elétrico e órgão.

De acordo com o informante e a observação de fotos da época, os instrumentos típicos da Bandinha Alemã, no início do século passado, eram: violino, flauta transversa, rabecão, contrabaixo, trombone de marcação, trompa e trompete. $\mathrm{O}$ clarinete também estava presente em algumas delas. O saxofone e a bateria vieram mais tarde. Atualmente, grande parte desses agrupamentos musicais da região sul do Brasil utilizam dois saxofones, dois trompetes, um surdo, uma gaita, um trombone e um tarol. Porém a significativa diversidade entre eles nos permitiu criar um agrupamento próprio, dentre as opções mais comuns.

Por fim, os instrumentos típicos do tango argentino são o bandoneom, o violino, o piano e o contrabaixo acústico, o qual pode ser tocado em pizzicato. Esses foram os timbres utilizados no arranjo desta forma de dança, presente entre os compassos 31 a 39. Mesmo sendo típico de algum desses estilos a música apenas instrumental, por se tratar de uma canção, todas as partes contém também linha de canto, por voz infantil.

\subsection{ASPECTOS PEDAGÓGICOS}

Diante dos avanços tecnológicos e epistemológicos, das informações quase instantâneas, da substituição de valores tradicionais da sociedade, e da globalização do mundo contemporâneo, evidencia-se que não há mais lugar para um pensamento fragmentado, linear, fechado e absoluto. Nesse contexto, surgem desafios por propostas interdisciplinares e construção cooperativa do conhecimento. O objeto virtual de aprendizagem Saladança de Frutas é um desses exemplos, aqui explicitado em seus aspectos musicais específicos às bases instrumentais da canção-tema.

Discutindo-se este relato de experiências à luz das diretrizes para produção de materiais didáticos recentemente estabelecidas pelo MEC, aponta-se para aspectos relevantes à produção desses materiais e seus componentes musicais para objetos virtuais de aprendizagem. De acordo com o MEC, (Brasil, 2007, p11):

Esses materiais didáticos para Web possibilitam integrar recursos e estratégias presentes em outras mídias, ampliando a capacidade de autonomia do aluno frente ao seu processo de aprendizagem em cursos a distância.

A produção dos componentes musicais Saladança de Frutas foi feita a partir de recursos computacionais, como softwares e simuladores (sintetizadores); no entanto, realmente relevante foi a experiência de tê-los criado em conjunto, no âmbito de uma proposta pedagógica de suporte. No caso, a Proposta Musicopedagógica CDG, amplamente apresentada pela Dra. Helena de Souza Nunes (2005), onde ocorre a busca pelo desenvolvimento ideal da autonomia, por intermédio de multiplicidade de recursos e modos.

\section{CONCLUSÃO}


A produção deste componente musical implica concepções para criação de trilhas sonoras destinadas a objetos virtuais de aprendizagem. Aponta-se a importância de aspectos como clareza sobre público-alvo e objetivos do objeto virtual de aprendizagem. Também a definição preliminar sobre softwares a serem empregados e o suporte mediante o qual a obra será veiculada, considerando a integração das diversas mídias envolvidas. Salienta-se a associação entre instrumentos naturais e sintetizados, assim como a associação deles com a voz humana. Também a definição por estilos e a coerência entre as sonoridades escolhidas para evidenciá-los é relevante, assim como o equilíbrio e a adequação entre o que é escutado e o que é visto deve ser levada em consideração.

\section{REFERÊNCIAS BIBLIOGRÁFICAS}

BASSANI, Patrícia. A necessidade de uma sociedade que saiba conviver: a contribuição da internet e da interdisciplinaridade. Revista de Estudos da FEEVALE. Novo Hamburgo - RS. No 1/2 V.23, 2000.

BENNÉT, Roy. Elementos Básicos da Música. In: General Musicianship, 4ªed. 1987, editora Cambridge University Press. Tradução de Maria de Resende Costa. Ed.Jorge Zahar, Rio de Janeiro, 1990.

. Instrumentos da Orquestra. In: Instruments of the Orchestra, $1^{\text {a }}$ ed. 1982, editora Cambridge University Press. Tradução de Luiz Carlos Csëko. Ed.Jorge Zahar, Rio de Janeiro, 1985.

BETTIO, R.W. e Martins, A. Objetos de Aprendizado: Um novo modelo direcionado ao Ensino a Distância". In: IX Congresso Internacional de Educação à Distância, 2002. Disponível em: <http://www.abed.org.br/congresso 2002/> Acesso em: 19 fev. 2008 .

BRASIL, Ministério da Educação - Secretaria de Educação Profissional e Tecnológica e Secretaria de Educação a Distância. Referenciais para Elaboração de Material Didático para EAD no Ensino Profissional e Tecnológico, 2007. Disponível em: <http://www.etecbrasil.mec.gov.br/gCon/recursos/upload/file/ref_materialdidatico.pdf> Acesso em: 18 fev. 2008.

GALlOTTA, Alexandre. Objetos da Aprendizagem: outra forma de ensinar. Programa Objetos de Aprendizagem, 2005. Disponível em: $<$ http://www.microsoft.com/brasil/educacao/parceiro/los_final.mspx> Acesso em: 18 fev.2008.

KIEFER, Bruno. Elementos da Linguagem Musical. Editora Movimento, $2^{\mathrm{a}} \mathrm{ed}$. Porto Alegre, 1973.

LUZ, Maikel da. O acompanhamento instrumental na canção infantil - a abordagem musicopedagógica CDG aplicada à canção Dias da Semana. Porto Alegre: UFRGS, 
2006. 32 f. (Trabalho de Graduação) - Graduação no Curso Licenciatura em Música, Universidade Federal do Rio Grande do Sul, Porto Alegre, 2006.

MEHLECKE, Querte Terezinha Conzi; TAROUCO, Liane Margarida Rockenbach. Ambientes de Suporte para a Educação a Distância: A mediação para aprendizagem cooperativa. Revista Novas Tecnologias na Educação. Porto Alegre - RS, v.5 , n.2, p.01-05, fev. 2003. Disponível em: $<$ http://www.cinted.ufrgs.br/renote/fev2003/artigos/querte_ambientes.pdf> Acesso em: 19 fev. 2008.

NUNES, César Augusto Amaral. Objetos de aprendizagem em ação. In Piconez, S. C. B. (Org.) . Educação \& Tecnologia \& Cidadania: Ambientes Virtuais de Aprendizagem no Ciberespaço - Série Cadernos Pedagógicos Reflexões. São Paulo, número 6. 1. p. ed., USP/FE/NEA / Artcopy, 2004. Disponível em: <http://www.moodle.ufba.br/mod/resource/view.php?id=1124 > Acesso em: 09 jan. 2008 .

NUNES, Helena de Souza. Musicalização de Professores. Livro do Professor. Porto Alegre: CAEF/UFRGS, 2005.

Musicalização de professores através da voz (MAaV). CAEF/UFRGS, 2005. Disponível em: <http://www.caef.ufgrs.br/produtos/ maav_prof > Acesso em: 09 jan. 2008.

PAVIANI, Jayme. Interdisciplinaridade: conceito e distinções. Porto Alegre: Pyr. 2005.

RANGEL, Annamaria Pífero et al. Teoria Pedagógica do Centro de Artes e Educação Física da Universidade Federal do Rio Grande do Sul: fundamentos do método empregado para a rede de formação continuada de professores. Porto Alegre: CAEF/UFRGS, 2005.

RANGEL, Annamaria Pífero; BARRETO, Umbelina; NUNES, Helena de Souza. Tutorial de Alfabetização através da Arte e da Educação Física. Porto Alegre: CAEF/UFRGS, 2005.

ROMISZOWSKI, Hermelina Pastor. Avaliação no Design e Desenvolvimento de Multimidia Educativa: estratégia de apoio ou parte do processo? In.: Anais do VII Congresso Internacional de Educação a Distância da Associação Brasileira de Educação a Distância - ABED, São Paulo, 2000. Disponível em: <http://www.abed.org.br/publique/cgi/cgilua.exe/sys/start.htm? UserActiveTemplate=4a bed\&infoid=184\&sid=102\&tpl=printerview > Acesso em: 18 jan. 2008.

TAROUCO, Liane; ÁVILA, Barbara. Multimídia na alfabetização digital com fluência para autoria. Revista Novas Tecnologias na Educação, Porto Alegre - RS, v.5, n.2, p.01-08, dez. 2007. Disponível em: 
co

<http://www.cinted.ufrgs.br/renote/dez2007/artigos/1Liane.pdf> Acesso em: 19 fev. 2008.

WILEY, David. Connecting learning objects to instructional design theory: A definition, a metaphor, and a taxonomy. In: The Instructional Use of Learning Objects. Ed. D.A. Wiley, 2000. Disponível em: <http://reusability.org/read/chapters/wiley.doc> Acesso em: 09 jan. 2008. 